\title{
The new trend in Science Communication research ecology: 2016 PCST conference review
}

Conference

Reviewed by

Abstract

Keywords

14 $4^{\text {Th }}$ Public Communication of Science and Technology (PCST) Conference: The Global Conference on Science Communication, ISTANBUL, TURKY, 26-28 APRIL 2016

\section{Kangyou Wang and Xuan Liu}

This is a conference review on PCST 2016 Istanbul.PCST 2016

Conference, with the theme of "Science Communication in Digital Age", was held in Turkey Istanbul on April 26, attracting more than 400 science communication experts and scholars from 52 countries and regions. This conference featured vast topics and rich contents, covering 6 conference reports, 52 sub-forums, 133 oral reports and 52 poster papers focusing on science communication changes, scientists participation, public object, ethics and art, tendency and policy under the background of the digital age.

Popularization of science and technology

PCST 2016 Conference, with the theme of "Science Communication in Digital Age", was held in Turkey Istanbul on April 26, attracting more than 400 science communication experts and scholars from 52 countries and regions. This conference featured vast topics and rich contents, covering 6 conference reports, 52 sub-forums, 133 oral reports and 52 poster papers focusing on science communication changes, scientists, participation, public objects, ethics and art, trends and policies, all under the background of the digital age. The conference reports discussed such issues as the relationship between science communication and political communication, media narrative and science communication, development and change within the field of science journalism, science communication skills and patterns for science expressions. There were also quite a few researches focus on comparison study of science communication strategy across countries and continents. In the sub-forums and seminars, researchers had lively discussions on the strategy, method and trends in science communication both from the theory and practice perspectives of science communication. Undoubtedly PCST Istanbul once again showed the rising prosperity of research in science communication and its growing maturity as a discipline, and it is not difficult to see several development trends in the field of PCST. 
Topic: traditional proposition is still hot and

"digitization" is attractive
The traditional research topics of science communication are still hot and many scholars pay attention to: the basic theory of science communication, theoretical discussions include quality, form, visual expression and strategy of science communication. Others still focus on the topic of public participation in science, and how to promote dialogue and interaction, public participation, social responsibility of scientists and how to carry out responsible scientific research are both hot topics discussed under this proposition. In addition, as traditional hot spots the relationship between science communication and other disciplines, such as science news, illustrate ongoing disputes in science communication, science communication technology and science and technology policies are still the major concerns in the circle.

\section{Presentations/Workshops/Panels}

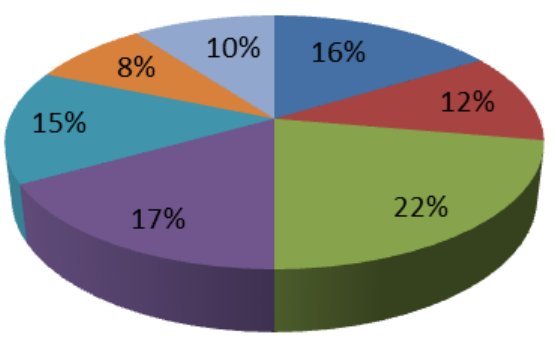

\author{
- Digital age \\ Ethics and arts \\ Publics \\ Scientists in PCST \\ Trends and Policies \\ - Media Practicies \\ - Participations
}

Figure 1. The distribution of presentations among topics.

We can also conclude from the topic coverage of PCST2016 that Publics and Scientists in PCST are still major subjects for researchers as shown in Figure 1. And Digital age and Media Practices include more and more research about new media and social media traditional topics still attract the attention of the academic community new trends in Informationalized and technological means of communication and the development of science communication in digital age evokes many new research topics. In the social media environment, the expression and effect of science communication remain of significant interest; science communication in digital age, with a series of new features and impact factors, requires not only to be deeply analyzed and studied from the theoretical level, but also to better apply digitization technology to traditional propositions of science communication based on the understanding of science communication law in the digital age. In addition, digitization provides favorable conditions to cover the development imbalance in science communication; in the discussion on digitization, there are science communicators from European countries, as well as researchers from Asian countries like Thailand, Iran and Indonesia. Science communication in the "digital" environment has gradually become another global issue in the field of PCST. 
Attended: improved balance in regional distribution and gender proportion
From the perspective of regions the European countries and the United States contributed the majority of research papers; however, developing countries also have outstanding performance, especially in the topic on case studies and development of science communication, researchers from Brazil, Argentina, Mexico, Southern Africa, Caribbean and India presented research. Therefore, although developed countries produced more research, the difference between developed countries and developing countries is gradually narrowing, and the regional distribution of PCST research is becoming more diversified.

Nevertheless, of the 6 keynote speakers, only 2 were female. But among the total representatives, the percentage of women has improved significantly. Meanwhile, more and more young researchers had the opportunity to express their research findings. There were quite a few Ph.D students who gave presentations on their staged results from ongoing research projects.

Methodology: the research method is also becoming more and more diversified, and discipline establishment has taken its shape

As an emerging interdisciplinary research field, the history of development of science communication is fairly short, and it has rather become a systematic research theory with unique research objects and scientific research methods, and has basically taken its shape as a mature disciplinary field. In terms of research methods, according to the issues discussed in the forums of this PCST conference of these studies have become dominant in science communication field research. and the report content, the empirical research, quantitative analysis and the results Case study, semi-structured interview, experimental research, questionnaire survey, data compilation and analysis, content analyses are still the research methods used frequently.

From the research perspective, most of the topics in PCST field are based on empirical perspectives, including deep case studies, online/offline questionnaire survey, observation experiment and field study. In the processing of investigation data, various sociology, statistics, text analysis and semantic analysis tools and application software are widely used for science communication research, which greatly improves the precision, depth and research efficiency of analysis. The common use of these research methods clearly shows that science communication, as an inter-discipliny field is highly multi-disciplinary (including sociology, psychology, pedagogy and management science) drawing on a range of empirical research and quantitative analysis tradition. However, as for disciplinary independence, science communication research relies on other disciplines greatly on theory and method. In that case the circle of science communication still needs deeper and more extensive reflection and discussion.

Established at the end of 1980s, PCST network organization was officially registered as a formal international academic organization in 2014, aiming to encourage the public science \& technology communication field to conduct research and discussion on career, culture, and international interdisciplinarity. Currently, PCST organization has more than 400 registered members coming from 52 countries and regions, including most of world's top scholars in the science communication field. Since 2012, PCST science committee has established documentation groups, which are dedicated to sorting out and protecting the 
historic literatures of PCST organization. This seeks to provide this literature to the academic community for exploitation and utilization. PCST Archive officially started to provide online services from 2016, integrating the papers and literature of all PCST conferences from 1989 to 2014, providing open access to PCST members. Currently, more than 1,400 conference papers or articles from the early stage of PCST are online, PCST literature data retrieval system is one of the most professional and rich conference literature resources in the international science popularization and communication fields at present. It offers rich research data and historical records for practice and research staff in this field.

In general, it is observed from the 2016 PCST conference that even though different economic, political and cultural backgrounds have a significant influence on the theory, method and practice of science popularization and communication, as with the continuous development of information in the world, the connection between nations or regions are increasingly close, and the science popularization and communication of all countries share many common points and consistent values. We are now seeing mutual learning from communication, both the "same" and "different" have a significant reference value for deep cognition within the science popularization and communication communities within countries. In the age of globalization, the science popularization and communication concept shall not focus on only one point, but on the science popularization and communication of the country from a world perspective based on historical depth, only in this way can a better result be obtained. PCST highlights the mutual understanding and comprehension necessity between science popularization and communication scholars from all countries in the age of globalization.

Wang Kangyou graduated from the department of geography of ancient geography in Beijing normal university. He is now the general director of China Research Institute for Science Popularization. E-mail: wangkangyou@cast.org.cn.

Liu Xuan got her Ph.D. degree from University for Science and Technology of China. She is now the associate professor in China Research Institute for Science Popularization. She was selected as the scientific committee member (under 35) of PCST in 2014. E-mail: liuxuan@cast.org.cn.

\section{How to cite}

Wang, K. and Liu, X. (2016). 'The new trend in Science Communication research ecology: 2016 PCST conference review'. JCOM 15 (06), R01. 